\title{
Ultrasound-Based Virtual Gynecological Endoscopy: What Next?
}

\author{
Jan Tesarik* \\ MARGen Clinic, Granada, Spain
}

Submission: August 20, 2017 ; Published: August 28, 2017

*Corresponding author: Jan Tesarik, MARGen Clinic, Camino de Ronda 2, 18006 Granada, Spain, Email: jtesarik@clinicamargen.com

\section{Opinion}

Virtual imaging has been gaining popularity in medical diagnosis over the past years. This also applies to the specialty of obstetrics and gynecology [1]. The most currently used techniques reconstruct virtual images of female reproductive organs from recordings obtained by computerized tomography, magnetic resonance and ultrasound scanning. As compared with the former two, the latter approach has the advantage of avoiding the exposure of patients to both ionizing radiation and intravenous contrast media [2] and has been suggested as an exclusive source of data for comprehensive evaluation of gynecological patients [3].

\section{Virtual Sono graphic Hysterosalpingoscopy}

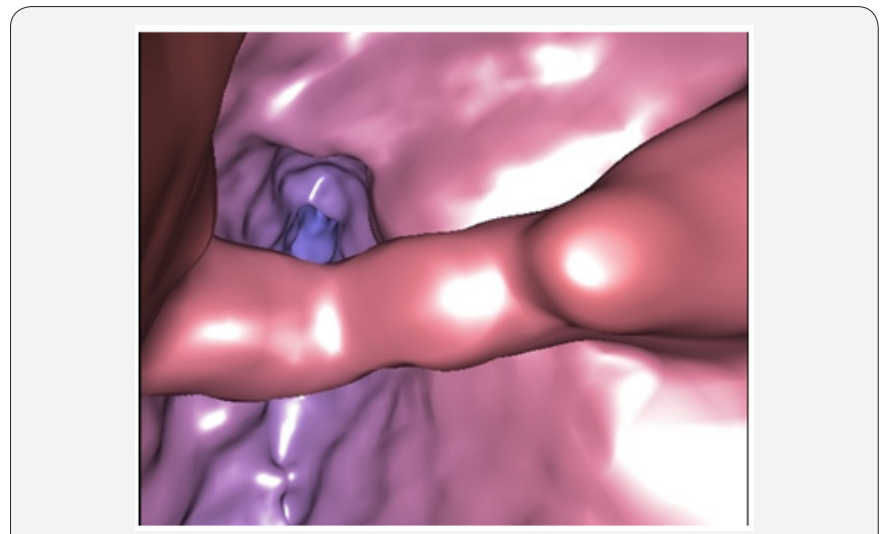

Figure 1: Virtual sonographic hysterocopy picture of the uterine cavity showing a synechia that takes the form of a beam-like, nearly horizontal intracavital adhesion crossing the cavity [4].

The introduction of Fly Thru technology (Toshiba) marked an important step in the development of gynecological virtual endoscopy techniques based on ultrasound. The potential of the Fly Thru technology in gynecological diagnostic workup has been first demonstrated for the examination of the uterine cavity. An intracavital anomaly (synechia), initially detected by virtual sonographic hysteroscopy, was subsequently confirmed by conventional hysteroscopy, and its removal enabled pregnancy in a woman with repeated unexplained implantation failures [4]. The shape and location of the synechia could be determined by virtual hysteroscopy with a precision even superior to that of conventional hysteroscopy imaging (Figure 1). Virtual sonographic hysteroscopy has subsequently been used as routine examination of women entering our assisted reproduction program, as a less invasive and more patientfriendly technique in comparison with the examination by conventional hysteroscopy.

\section{Virtual Sono graphic Hysterosalpingoscopy}

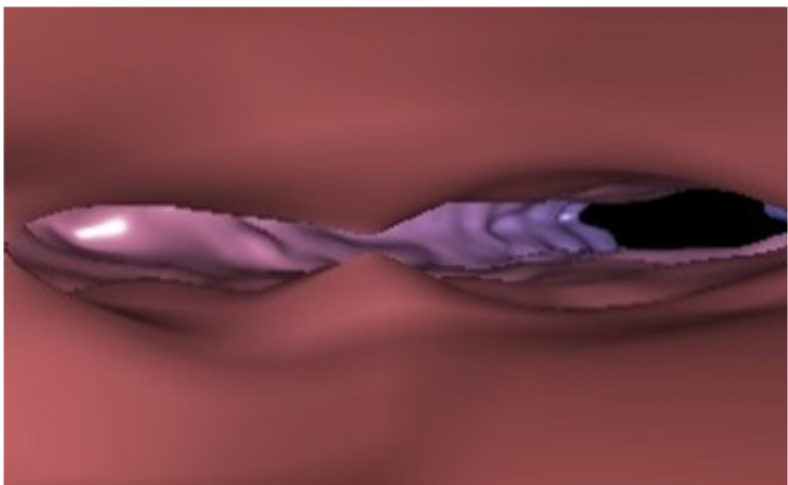

Figure 2: Virtual Sono graphic Hysterosalpingoscopy image in a woman with blood in the uterine cavity and suspected tubal pregnancy, which was later confirmed. The proximal ostium of the affected tube (Wright in the picture) shows an asymmetric dilatation [5].

Virtual hysteroscopy does not need the introduction of instruments into the uterine cavity, as is the case for conventional hysteroscopy, and all recordings are taken by a vaginal ultrasound probe, as for the routine vaginal gynecological examination. However, the visualization of the uterine cavity requires the injection of a small amount of saline to separate the cavity walls and expose the endo cavital surfaces. Further progress in the virtual sono graphic technologies for the evaluation of the cavities and canals of female reproductive organs was marked by 
the observation that spaces spontaneously filled with blood can be examined by Fly Thru without injecting saline. In fact, blood is anechogenic and can serve as natural filler fluid for ultrasound examination of body cavities and canals. Accordingly, the uterine cavity can be examined by virtual hysteroscopy without any preparatory treatment in cases of uterine bleeding (Figure 2). In cases of tubal pregnancy, the affected fallopian tube, filled with blood, can also be identified (Figure 2), and the tubal canal can be followed as continuation of the uterine cavity up to the site of the ectopic implantation site, enabling a direct visualization of the embryo [5]. This technique has been named virtual sonographic hysterosalpingoscopy.

\section{Virtual Sonographic Embryoscopy}

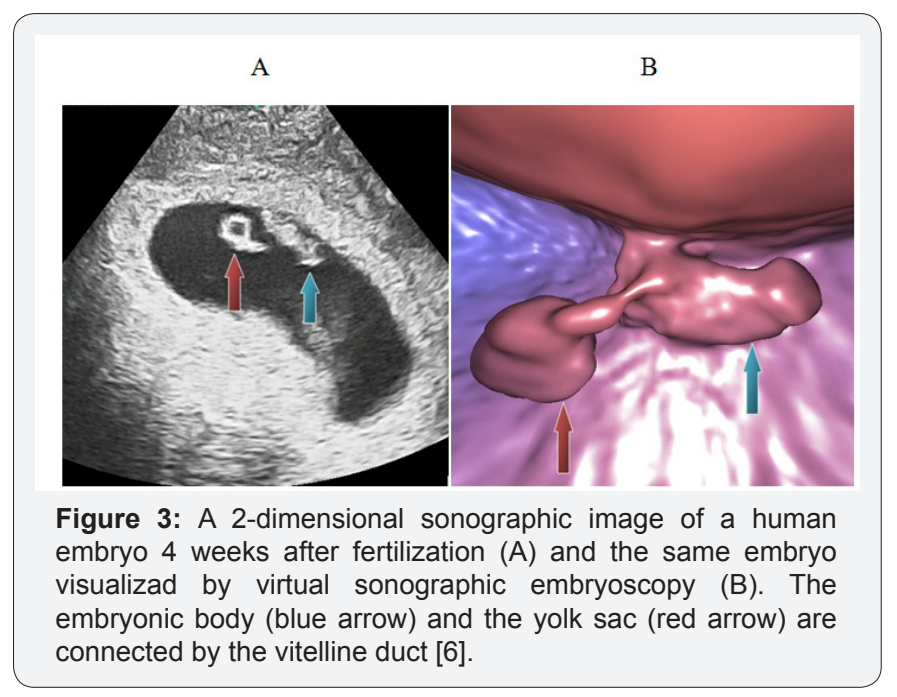

Embryos recently implanted in the uterus can also be visualized by virtual sonographic imaging. The examination of the gestational sac and its content is conventionally performed with the use of 2-dimensional or 3-dimensional ultrasound scanning. However, these structures are also perfectly susceptible to be analyzed by Fly Thru technology. The first study using this approach has shown that the images created by this technique (Figure 3), named virtual sonographic embryoscopy, offer a higher precision and spatial resolution as compared to conventional ultrasound [6]. These characteristics appear to be useful to improve the early prediction of the risk of embryonic demise. This is also the first demonstration showing that virtual sonographic endoscopy can be adapted to the study of body cavities that are not accessible to conventional endoscopy as an alternative.

\section{What Next?}

There are other cavities and canals in the female reproductive system which might be prone to the study by virtual sonographic endoscopy. The antral cavity of large ovarian follicles may be analyzed for the presence of the cumulus-oocyte complex, in order to distinguish between true follicles and cysts. This may be of help in the context of ovarian stimulation for in vitro fertilization, namely in patients with the history of empty follicle syndrome and in patients with poor ovarian response, in whom the decision has to be taken if it is worth performing follicle aspiration or if the cycle should rather be canceled. The cavity of the urinary bladder is also accessible to Fly Thru imaging, and virtual sonographic cystoscopy may thus become an alternative to conventional cystoscopy one day.

All the virtual endoscopy techniques referred to in this paper have been described recently, and more data is needed to evaluate their real significance in different clinical settings. If the information which can be obtained with these techniques is comparable with that from conventional endoscopy, virtual sonographic endoscopy will certainly continue to gain positions in the clinical diagnostic workup because of its noninvasive and patient-friendly nature.

\section{References}

1. Sella $T$, Laufer $N$ (2016) Introduction: Imaging in reproduction. Fertil Steril 105(6): 1379-1380.

2. Hershko-Klement A, Tepper R (2016) Ultrasound in assisted reproduction: a call to fill the endometrial gap. Fertil Steril 105(6): 1394-1402.

3. Grosmann YZ, Benacerraf BR (2016) Complete evaluation of anatomy and morphology of the infertile patient in a single visit: the modern infertility pelvic ultrasound examination. Fertil Steril 105(6): 13811393.

4. Tesarik J, Mendoza-Tesarik R, Mendoza N (2017) Virtual ultrasonographic hysteroscopy followed by conventional operative hysteroscopy, enabling pregnancy. Am J Obstet Gynecol 216: 188.e1.

5. Tesarik J, Mendoza-Tesarik R, Mendoza N (2017) Virtual sonographic hysterosalpingoscopy for ectopic pregnancy detection. J Gynecol Obstet 1:002.

6. Tesarik J, Mendoza-Tesarik R, Mendoza N (2017) Virtual sonographic embryoscopy: a new tool for evaluation of early pregnancy. EC Gynaecology 5.2: 69-71. 
Your next submission with Juniper Publishers will reach you the below assets

- Quality Editorial service

- Swift Peer Review

- Reprints availability

- E-prints Service

- Manuscript Podcast for convenient understanding

- Global attainment for your research

- Manuscript accessibility in different formats

( Pdf, E-pub, Full Text, Audio)

- Unceasing customer service

Track the below URL for one-step submission https://juniperpublishers.com/online-submission.php 